\title{
ESV Measurement-The Opportunity Cost of Land Development
}

\author{
Liuyi Yang ${ }^{1, \text { a }}$, Yanqi Zhao ${ }^{2, b}$ \\ ${ }^{1,2}$ Northeast Normal University, No. 5268 Renmin Street, Nanguan District, Changchun, Jilin, 130024, China
}

\begin{abstract}
Ecological systems are essential in maintaining a good living environment for human beings. However, human beings usually focus on the benefits they can gain from the ecosystem by developing the land and ignore the degradation of environment. In this paper, we will offer an ecological services evaluation model to measure the value of ecological services and provide land use planners with a method to compute the true economic costs of the land use development projects. First, we define ecological services value (ESV), which means the value of the benefits that ecosystem can provide. Then, we classify the functions of ecosystem into five kinds: water purification, climate regulation, air purification, biodiversity conservation and vegetation conservation. For each function, we choose a related index to measure the performance. After the classification, we adopt Analytical Hierarchy Process (AHP) to calculate the weight for each of the function and do the consistency test; second, we apply knowledge of economics to study the true economic costs; third, after getting the equation of the true economic costs, we realize it in the cost-benefit analysis. We offer two case studies to analyze the small community-sized project and large national project respectively; fourth, we take ten examples including U.S., Switzerland and China to apply our model in practice. We fit data and find the average level of land use percent over time, and form a model with differential equation in order to calculate the time-varying model of ESV; fifth, we focus on humanities field to explore the impacts on land use project planners and managers. They should not only be responsible for environmental degradation and monitor environmental index carefully, but also pay for the benefits which were ever owned by human beings before land development. In order to make our work more accurate and complete, we use SWOT Analysis across the analytical process. Finally, we promote our model and extend the factors from six to twelve, which increases the accuracy.
\end{abstract}

\section{Introduction}

\subsection{Background}

On Jan.24 $4^{\text {th }}$, 2019, the United Nations Environment Programme (UNEP) released the world's first assessment report on the rule of law. The report points out that despite the environmental laws are continuously increasing in the past 40 years; the trend of weak law enforcement has aggravated the environmental threat. The situation cannot just be considered as the civil workers' corruption and low administrative efficiency, the environmental evaluation is also a factor which the government should focus on.

Broadly speaking, people do not have to consider the impact of ecosystem service when evaluating the overall potential of biosphere function. However, this kind of incomplete evaluation method often leads to the deviation of results, which affects the government's judgment and helps them to prevent decision-making mistakes in domains of economic, policy and legal. Our task is to discover the external and internal value of

\footnotetext{
a E-mail: 936549391@qq.com, ${ }^{b}$ E-mail: 1148078779@qq.com
}

ecosystem services and reassess the ecosystem. In order to solve this problem; we must establish a complete ecological service evaluation model which plays an important role in. However, in the process of assessment, we are facing two difficulties:

(1) Eco-service system refers to all the benefits of human beings from the ecosystem, which includes supply services, spiritual and cultural services, regulation and control services and maintenance of circular services. In fact, these factors are hard to quantify and measure in detail.

(2) The main factors affecting the environment (water quality, air quality, vegetation coverage, etc.) are interrelated and complementary to each other to a certain extent. As a result, our model is a little vague here, but it is undeniable that the valuation model is the result of five factors working together.

\subsection{Our Works}

Considering the background of this topic and the related research achievements, we decide to design an Ecological Services Valuation Model utilizing Analytical Hierarchy Process (AHP) to provide a clear and easily 
understandable method to measure the benefits that ecosystem offered freely to human beings. The five steps of our process to solve the problems are as follow:

(1) Set Reasonable Assumptions and Clear Acronyms

Due to the diversity of ecosystem and the difficulty in quantifying the benefits of ecological services, we set a series of assumptions to unify the ecological benefits of the undeveloped land we study, and the data sources and the factors that we do not consider in our model are also regulated in our assumptions.

(2) Develop an Ecological Services Valuation Model

We use Analytical Hierarchy Process (AHP) to develop our valuation model. We focus on five aspects of the functions of ecosystem and calculate the weight of each part. Our valuation model can be used to assess a country's ecosystem by calculating its five kinds of ecological benefit indexes and get the country's ecological services value.

(3) Calculating the Cost of Environmental Degradation. We introduce the environmental performance index as an intermediate variable to find the correlation between ecological services value and the cost of environmental degradation. The data that we use in this section is from different countries, so we use the methods of data normalization and standardization to preprocess the data.

(4) Do Cost-benefit Analysis

In cost-benefit analysis, we adopt net present value analysis and make some promotions on it. We add the cost of environmental degradation on the cost section, so the cost in our cost-benefit analysis is the true economic cost. In order to make our model more understandable, we use two cases to illustrate the difference between large national projects and community-based project.

(5) Model evaluation and promotion

We list the strengths and weaknesses of our model, and the promotional version which includes more indexes will be also discussed.

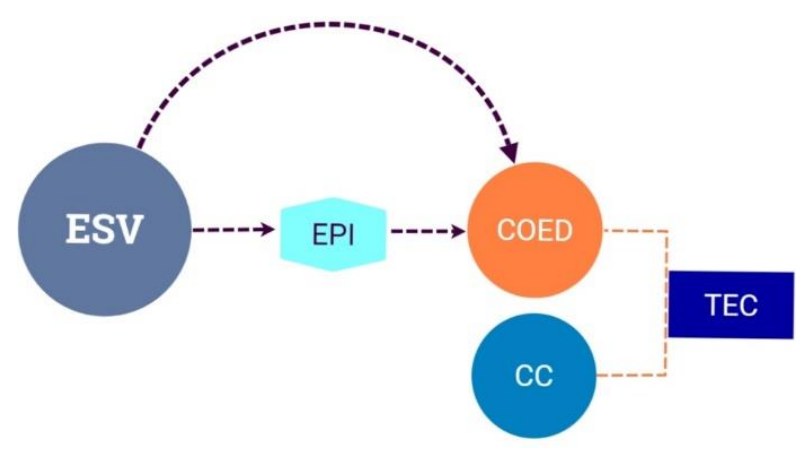

Figure 1: Our Process

\section{Assumptions and Symbols}

\subsection{Assumptions}

We make following assumptions about data sources, research objects and the factors we need to consider in the ecosystem service valuation model, so we can simplify the complicated research problem to a certain extent and make our model more adoptable to the real conditions.

\subsection{Symbols}

\begin{tabular}{|c|c|c|c|}
\hline Symbols & Definition & Symbols & Definition \\
\hline AQI & Air Quality Index & CC & Common Cost \\
\hline CCPI & The Climate Change Performance Index & TEC & True Economic Cost \\
\hline BI & Biodiversity Index & GNH & Gross National Happiness \\
\hline WCI & Water Clarity Index & FS & Food Service \\
\hline VCI & Vegetation Coverage Index & RND & Resistance to natural disasters \\
\hline ESV & Ecological Services Value & NHI & National Health Index \\
\hline CS & Cultural Services & EL & Education Level \\
\hline EPI & Environmental Performance Index & WCR & Water Circulation Rate \\
\hline COE & Cost of Environment & SS & Supply Services \\
\hline RS & Regular Services & SS & Support Services \\
\hline FWS & Fresh Water Supply & & \\
\hline
\end{tabular}

\section{Model}

Ecosystem Services are the many benefits and assets that humans receive freely from our natural environment and a fully functioning ecosystem. ${ }^{[1]}$

\subsection{Ecological Services Valuation Model}




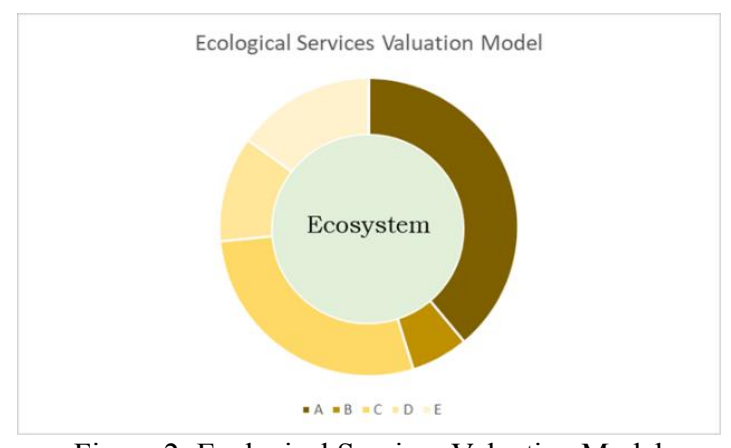

Figure 2: Ecological Services Valuation Model

\subsection{Main Categories of Ecological Services}

In this section, we will demonstrate each part of the functions of ecosystem, and five indexes will beintroduced for each function respectively. We collect data for each index of different countries around the world. In order to unify the form of these data, we do some work on the data preprocessing, such as data normalization and data standardization, which will be mentioned in the corresponding indexes.

\subsubsection{Water Purification}

In Journal of water ecology, issue 01, 2016, it mentions that as one of the world's three major ecosystems, wetland has water purification function which can effectively improve the quality of regional ecological environment. ${ }^{[2]}$

\subsubsection{Climate Regulation}

The role of ecosystem in climate regulation cannot be ignored. We use the Climate Change Performance Index (CCPI) to quantify the climate regulation function. The more unstable the climate is, the higher the climate index is, which means the weaker the regulating function of the ecosystem is.

\subsubsection{Air Purification}

We use the Air Quality Index (AQI) to measure the air purification function. The air quality index is divided into five grades according to the numerical magnitudes. When the number is between 0 and 50 , it is defined as the air quality is satisfactory, and there is basically no air pollution; if the number is over 300 , it means severe air pollution.

\subsubsection{Biodiversity Conservation}

Biodiversity reflects the state of the ecosystem of a certain area. A healthy ecosystem has a strong function of maintaining biodiversity. We use data normalization and standardization to change the number of biodiversity into Biodiversity Index (BI).

\subsubsection{Vegetation Conservation}

We use the Vegetation Coverage Index (VCI) to value the vegetation conservation function of ecosystem.

\subsection{Analysis Hierarchy Process}

Analysis Hierarchy Process (AHP) is a simple, flexible and practical multi-criteria decision-making method proposed by professor t. 1. Saaty, an American operational research scientist, in the early $1970 \mathrm{~s} .{ }^{[3]} \mathrm{We}$ used this method to achieve quantitative analysis of ecological services.

\section{True Economic Costs}

For a land use development project, people usually accounting the costs called explicit cost, which means the money cost of the equipment, labor, operating and construction, so the cost of the destruction of ecosystems is neglected. There is always an opportunity to give up one business for another. In economics, the other revenue to be derived from an operating activity is the opportunity cost of the ongoing operating activity. ${ }^{[4]}$ Similarly, when people develop the land, people lose the opportunity to gain the ecological services that the land provide, so we can regard the cost of environmental degradation as the opportunity for land use development project. We define the original accounting cost as Common Cost (CC), the opportunity cost for land use development projects as Cost of Environmental Degradation as (COED), and the total cost as True Economic Cost (TEC).

\section{Cost-benefit Analysis}

Cost-benefit analysis is a method to assess the value of a project by comparing the total cost and benefit of the project. ${ }^{[5]}$ Net Present Value (NPV) is the method we use in the cost benefit analysis. We add the COED into the cost, so the environmental factors are considered in the analysis.

\subsection{Case Study of Projects of Different Scales}

\subsubsection{Small Project: Brownfield Restoration- Reading, Connecticut as an Example}

Brownfield, in contract to greenfield, means exploited and utilized field. (Greenberg et al., 2001), which is also the product of industrialization. Brownfield, in this instance, will be explained as the land that idle, polluted and capable for re-exploration. All the analysis will use the number from year 2018, although money has the timing value and there is difference for lacking precious number for this project. So, here assume there is only a Walmart for making profits, all other facilities are supplements. According to the Walmart's financial report of year 2018, the net profit was 9.8 billion dollars in total, with a corporation tax rate of $20 \%$ (without 
considering any tax benefits to Walmart). Hence, the table below shows the cost-benefit analysis with financial factors from the perspective of the federal government. Here, "B/C Ratio" is created similar to
ROCE, which helps to make an investment decision with presenting how much return would occur with one-unit investment, so if the number of $\mathrm{B} / \mathrm{C}$ Ratio is bigger than 1 , the project should be invested with a return.

Table 1: Cost-Benefit Analysis on this project with Financial Factors

\begin{tabular}{|c|c|c|}
\hline \multicolumn{3}{|c|}{ Cost-Benefit Analysis } \\
\hline & $\$^{\prime} \mathrm{m}$ & $\$^{\prime} \mathrm{m}$ \\
\hline Taxation & 1.96 & $(1.1)$ \\
\hline Costs & & \\
\hline B/C Ratio & 1.78 & \\
\hline
\end{tabular}

From the data shown in the table, the B/C Ratio tends to be a number greater than one, therefore, as for the government, it is an effective project deserve the investment.

\subsubsection{Large Project: Tennessee Valley Comprehensive Development Projects}

Tennessee Valley Comprehensive Development Projects were conducted by U.S. Federal Government, which utilized all possible resources based on the actual situations and conditions of the Tennessee River. The following is four stages whicharefor developing Tennessee River operated by TVA:

Stage 1: 1933-1950. Based on flood controlling facilities and shipping transportation, the adequate hydro-power resourcesattracted operators and investors to build dams and water conservancy pivots, which helped to prevent the detriment to innocent citizens and agricultural land there and increase the agricultural income through controlling flood.

Stage 2: 1950-1960. The number of dams and hydrojunctions require large amount of energy to support its daily operation. In hence, the thermal power stations and hydropower stations were going up.

Stage 3: 1960-1970. With the continuous research and development on nuclear power, thermal power stations were built in a slow speed, and a few reservoirs are built on tributaries.

Stage 4: After 1970. As the successive development of nuclear power goes to be mature, nuclear power plants became popular, with the well-known Large Pumped Storage Hydropower Station at Mount Lakong.

Through the efforts made on it, up to now, there are 54 reservoirs ( 27 of them having the ability to control flood) in total, whichlengthofthe total volume of 29 million cubic meters. At the end of $20^{\text {th }}$ century, tremendous flood prevention brought 5 billion dollars as a benefit. All the numeral benefits can be concluded as follow in Table 2:

Table 2: Benefits from Tennessee Valley Comprehensive Development Projects

\begin{tabular}{|c|c|}
\hline \multicolumn{2}{|c|}{ Benefits from TVCDP } \\
\hline & \$' billion \\
\hline Gains from Agriculture & 5 \\
\hline Gains from Electricity & 6.6 \\
\hline Gains from Shipping & unknown \\
\hline Total & $11.6+$ \\
\hline
\end{tabular}

On the other hand, the price for rapid economic growth is to sacrifice the ecological balance. Therefore, there is no attention paid on environmental bearing capacity until late 1980 s, the time when the operators were about to highlight the significance of a good environmental condition.

\section{How Our Model Changes Over Time}

In order to find the internal relationship between land area change rate and five factors, we find data and draw out the picture below. Since the ten countries we are looking for include many big countries, they are almost the same size as the global total area. As a result, our research assumes the average of ten countries' data is the same as the world's. Obviously, the land use rate is increasing rapidly over time, which means that the percent of developed land is increasing all over the world. 


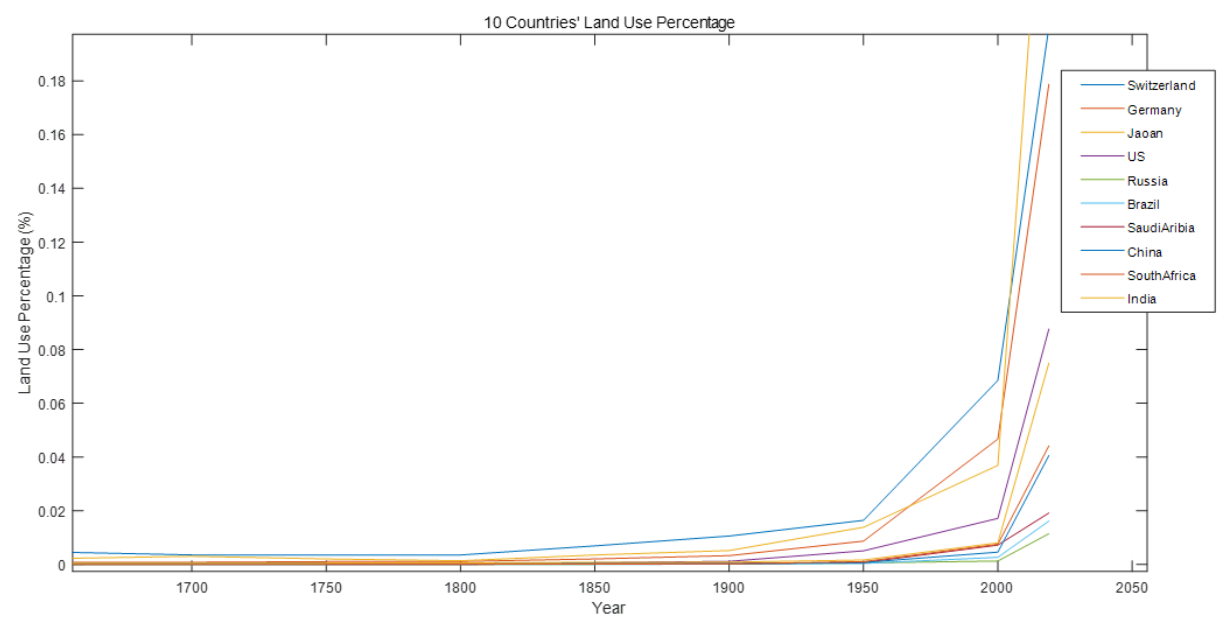

Figure 3: 10 Countries' Land Use Percentage [11]

We define "S" as the change rate of the cost by years, which means opportunity cost in the process of land development in ecological service valuation model.

$$
S=\frac{E S V_{2}-E S V_{1}}{E S V_{2}} \times \frac{\triangle M}{Y_{2}-Y_{1}} \times 100 \%
$$

In order to solve the model, we estimate the parameter $\hat{t}$, which measures the degrees of five factors in ESV, by using data in the past $Y_{2}-Y_{1}$ years by the least square method. We denote residual error by $e$. assume

$$
e=\Delta M_{Y_{2}-Y_{1}}-\hat{t} S_{Y_{2}-Y_{1}}
$$

$\triangle S_{Y_{2}-Y_{1}}$ can be easily obtained from

$$
\Delta S_{Y_{2}-Y_{1}}=\left[\begin{array}{c}
\frac{d W C I}{d\left(Y_{2}-Y_{1}\right)} \\
\frac{d C C P I}{d\left(Y_{2}-Y_{1}\right)} \\
\frac{d A Q I}{d\left(Y_{2}-Y_{1}\right)} \\
\frac{d B I}{d\left(Y_{2}-Y_{1}\right)} \\
\frac{d V C I}{d\left(Y_{2}-Y_{1}\right)}
\end{array}\right]_{Y_{2}-Y_{1}}=\left[\begin{array}{l}
W C I_{Y_{2}-Y_{1}+1} \\
C C P I_{Y_{2}-Y_{1}+1} \\
A Q I_{Y_{2}-Y_{1}+1} \\
B I_{Y_{2}-Y_{1}+1} \\
V C I_{Y_{2}-Y_{1}+1}
\end{array}\right]-\left[\begin{array}{l}
W C I_{Y_{2}-Y_{1}} \\
C C P I_{Y_{2}-Y_{1}} \\
A Q I_{Y_{2}-Y_{1}} \\
B I_{Y_{2}-Y_{1}} \\
V C I_{Y_{2}-Y_{1}}
\end{array}\right]
$$

Based on the data published by some authorities, we find that the trend of changing is continuing. Our prevailing premise shows that the weights which are given to the five factors in our model are straight and accurate. However, after we check the weights of five factors and the degrees that they can help to form an ecological equilibrium situation are easy to change in a long time. We set the world average land use as an example, and we find that their attentions on CCPI is increasing and which on AQI is decreasing. It not only depends on the federal law, but also because of the changes of environmental measurements. No model can remain the same in perpetuity. As the rapidly increasing urbanization, the model is unstable in front of people. As a result, we fitted the data we have obtained and predict the model in 2050, which help us find the new weights of the model. In Figure 6, the red zone shows the future situation.

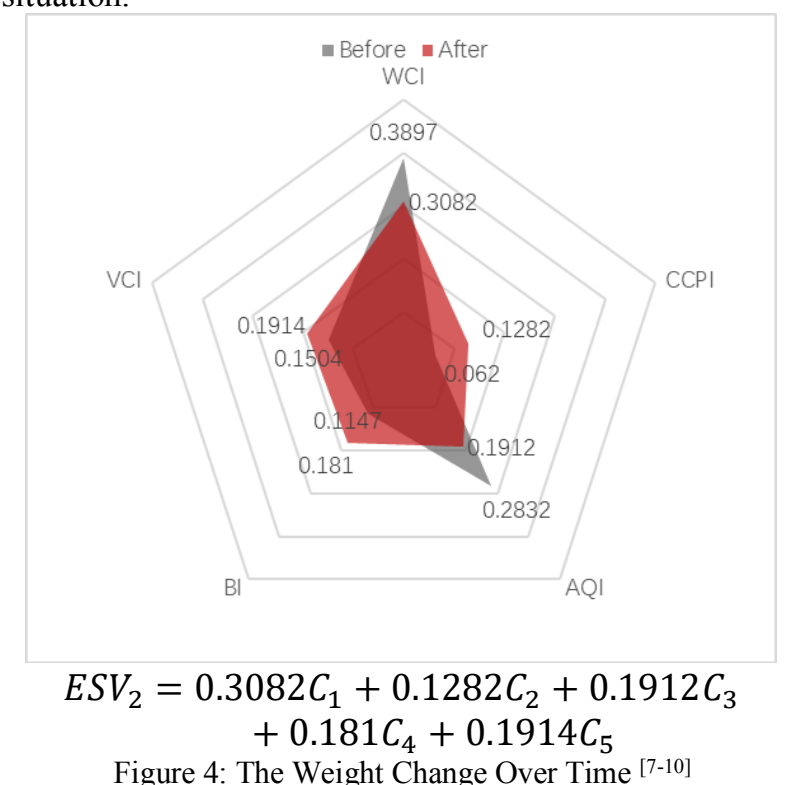

\section{The Implications of Our Modeling on Land Use Project Planners and Managers}

Based on our model, although the main factors seem that they almost have no relationship with so-called "outsiders", some people's behaviors and benefits are also be reflected. 


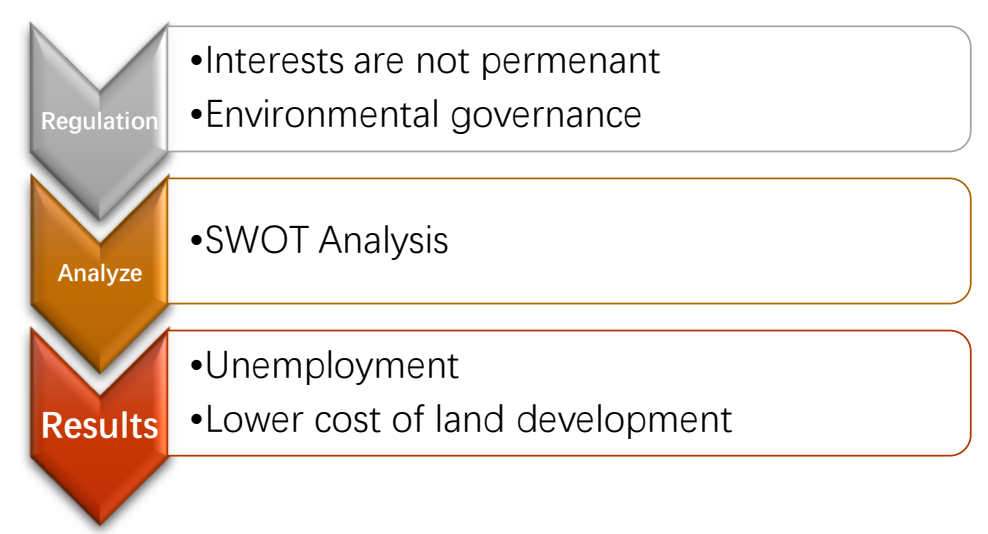

As a tool for assessing the current situation, SWOT Analysis is used by many companies in modern society. Its magic is that it can analyze four factors at the same time, and put them in the matrix for analysis and comparison. SWOT analysis does not only check the situation, but also help people to evaluate some behaviors under the challenging and complexed society. In order to make right decisions under the dangerous environment and evaluate the implications of our model on land use project planners and managers, the following figure is showing the impact of ecosystem service model on the project planners and managers.

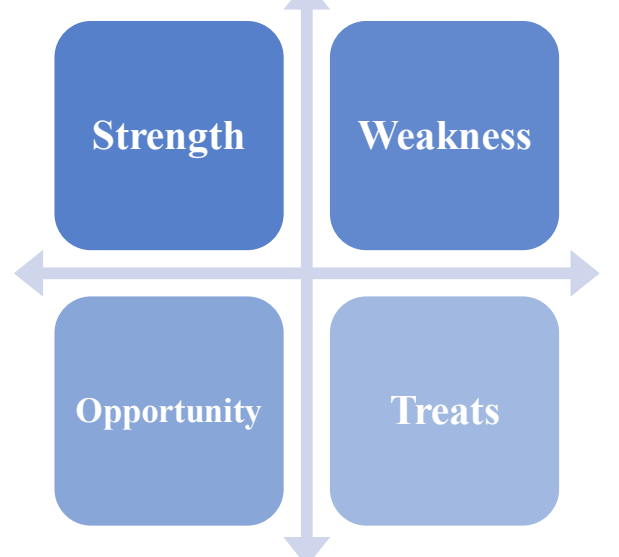

- Strength: The land is developed by the land use project planners, so the benefits from operating the factories/communities will all belong to developers.

- Weakness: Planners and managers have fewer opportunities to develop deeper in that field, such as using equipment which causes air pollution or water pollution. Their profit will be lower.

- Opportunity: As the inflation and the increase of exchange rate, the cost of constructing is higher, which can increase the liquidations.

- Threats: Under the government regulation, the random environmental samplings and high-pressure environmental protection both make them feel scared. Also, their employees will lose the chances to work, which causes unemployment.

\section{Strengths and Weaknesses}

\subsection{Strengths}

(1) Combine the Knowledge of Economics and Ecology

In the process of computing the true economic costs, we define the cost of environmental degradation as opportunity cost which is created by early Austrian economistFriedrich von Wieser in his book Theorie der gesellschaftlichen Wirtschaft. ${ }^{[6]}$

(2) Clear and Rational Classification

In the analytical hierarchy process, we divide the ecological services into five sections based on the different kinds of functions of the ecosystem. We adopt the pie chart to illustrate the hierarchy of our model to make the classification clear and easy to understand.

(3) The Reliability of the Model

Before establishing our model, we collect the related data from a series reliable sources and preprocess these data by doing data normalization and standardization, so this step improves the reliability of our data andmodel.

\subsection{Weaknesses}

\section{(1) The Missing Factors}

In our assumptions, we assume that all the areas we study have the same degree of providing ecological services in different functions, so we neglect the influences that the different degrees of ecosystem may have.

\section{(2) The Interplay between the Indexes}

The five indexes we choose may have some impacts among them. It is difficult to separate these factors completely.

\section{Promotions}

Generally speaking, the model we established can clearly and accurately express the impact of ecosystem service, which is neglected by people in the past. Actually, we consider that there are four aspects including Regular Services (RS), Supply Services $\left(S S_{l}\right)$, Cultural Services $(C S)$ and Support Services $\left(S S_{2}\right)$, which bring impacts on ecosystem service with different weights. Meanwhile, there are many factors which are involved in four kinds of services make changes on ecosystem service valuation. In Regular Services (RS), we can see $W C I$, CCPI, $A Q I$, $V C I, R N D$ and National Health Index (NHI) as main factors. In Supply Services $\left(S S_{I}\right)$, Food Service (FS) and Fresh Water Service (FWS) are also reasons which 
affects ecosystem service valuation. Also, we find Educational Level (EL) and Gross National Happiness $(G N H)$ as factors of Cultural Services (CS). At last, inSupport Services $\left(S_{2}\right)$, the Water Circulation Rate $(W C R)$ and $B I$ are both persuasive factors in evaluating ecosystem service. However, it is a great pity thatsome factors in this part, such as spiritual and cultural processes and some functions to control the ecological cycle are difficult to quantify.

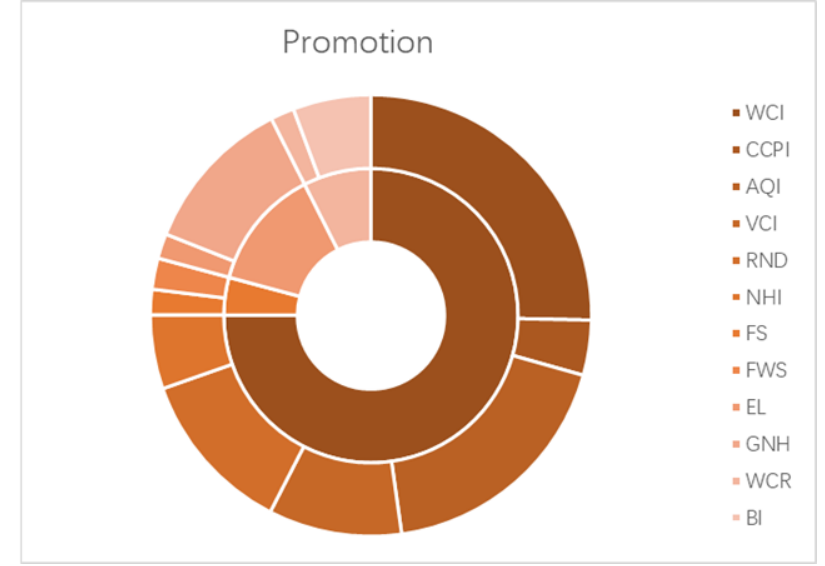

Figure 7: Promotion ${ }^{[7-10]}$

In order to show both the external performance and inherent value, we seek to facilitate the implementation of the complex evaluation system.

\section{Fund Project}

The Fundamental Research Funds for the Central Universities (Project No.: 201910200111804).

\section{References}

1. https://www.baidu.com/link?url=5bAEidA8oQuU4 NP7faGMsJMrysHhLsIwMux8Ywi2cw2zuMTfWK jag5Wukp6xVIf0eb8hoXi7tpl1f1M_OJQ63a\&wd= \&eqid $=\mathrm{db} 289 \mathrm{cf} 100004967000000025 \mathrm{c} 4 \mathrm{f} 426 \mathrm{a}$.

2. As one of the world's three major ecosystems, wetland has water purification function which can effectively improve the quality of regional ecological environment.
http://mall.cnki.net/magazine/Article/SCAN2016010 05.htm.

3. Analysis Hierarchy Process (AHP) is a simple, flexible and practical multi-criteria decision-making method proposed by professor t. 1. Saaty, an American operational research scientist, in the early 1970s.

https://baike.baidu.com/item/\%E5\%B1\%82\%E6\%A C\%A1\%E5\%88\%86\%E6\%9E\%90\%E6\%B3\%95/16 72 ? fromtitle $=$ AHP\&fromid $=1279008$.

4. The other revenue to be derived from an operating activity is the opportunity cost of the ongoing operating activity. https://baike.baidu.com/item/\%E6\%9C\%BA\%E4\% BC\%9A\%E6\%88\%90\%E6\%9C\%AC/498896? fr=al addin.

5. Cost-benefit analysis is a method to assess the value of a project by comparing the total cost and benefit of the project. https://baike.baidu.com/item/\%E6\%88\%90\%E6\%9 C\%AC\%E6\%95\%88\%E7\%9B\%8A\%E5\%88\%86\% E6\%9E\%90/5555681

6. From early Austrian economist Friedrich von Wieser in his book Theorie der gesellschaftlichenWirtschaft. https://zhidao.baidu.com/question/20765096142157 53508.html.

7. https://germanwatch.org/sites/germanwatch.org/files /CCPI2019_Results.pdf.

8. World Conservation Monitoring Centre of the United Nations Environment Programme (UNEPWCMC), 2004. Species Data (unpublished, September 2004).

9. https://www.kuaiyilicai.com/stats/global/yearly_over view/g_area_forest.html.

10. Yale Center for Environmental Law \& Policy, Earth Institute | Columbia University Center for International Earth Science Information Network, 29th April 2018 https://epi.envirocenter.yale.edu/epicountries.

11. OurWorldinData https://ourworldindata.org/charts 